\title{
Quadricuspid Aortic Valve by Transthoracic Echocardiography
}

\author{
Erlon Oliveira de Abreu Silva ${ }^{1}$, Alessandro Giralde Iglesias², Erlon de Abreu Silva² \\ Complexo Hospitalar Santa Casa de Porto Alegre1, Centro de Diagnóstico Cardiológico², Porto Alegre, RS, Lages, SC - Brazil
}

A 55-year-old woman seeks medical attention with palpitations, atypical chest pain and dyspnea upon exertion, lasting for 12 months. ECG showed left ventricular hypertrophy.

Transthoracic Doppler echocardiogram confirmed hypertrophy of the left chambers and showed a quadricuspid aortic valve, with equal-sized cusps, in addition to a moderate regurgitant central flow.

Upon echocardiography, the quadricuspid valve is identified by its characteristic " $\mathrm{X}$ " form during diastole and rectangular aspect during systole. Heart failure symptoms are presumably caused by valve insufficiency due to abnormal leaflet coaptation.

Considering the possibility of progressive regurgitation, follow up on the patient was performed with periodic echocardiographic control. Symptoms responded to treatment.

\section{Introduction}

Quadricuspid aortic valve is a rare finding, with an incidence varying between 0.008 and $0.033 \%{ }^{1}$, and, in general, is not associated with other conditions. The first related cases were based on necropsy, aortographic or perioperative findings ${ }^{2}$.

More recently, echocardiography, especially with Doppler, has facilitated early diagnosis of four-cusp aortic valves, evaluation of their function and follow-up.

Our purpose is to report the incidental finding of a quadricuspid aortic valve by transthoracic Doppler echocardiography in a case of valve regurgitation.

\section{Case Report}

A 55-year-old woman seeks medical attention with palpitations, atypical chest pain and dyspnea upon exertion, for the 12 previous months. There is no prior history of

\section{Key words}

Aortic valve / abnormalities; aortic valve insufficiency; echocardiography.

\section{Mailing Address: Erlon Oliveira de Abreu Silva •}

Rua Casemiro de Abreu, 725/302, Rio Branco, 90420-001, Porto Alegre,

RS - Brazil

E-mail: erlon@terra.com.br

Manuscript received August 7, 2007; revised manuscript received September 5, 2007; accepted September 26, 2007. rheumatic fever, hypertension or other comorbidities. Upon examination, heart rate was 84 , blood pressure 130x80 $\mathrm{mmHg}$, and there was a diastolic murmur at the aortic position $(3+/ 6+)$. Chest radiograph revealed augmented cardiac area and the 12-lead ECG showed left ventricular hypertrophy.

Transthoracic echocardiogram revealed moderate left ventricular enlargement and preserved ejection fraction. The mitral valve had a minimum prolapse of the anterior leaflet, with no dysfunction. Tricuspid and pulmonary valves were normal. The aortic valve had four equal-sized cusps (Figures 1), and a moderate regurgitant central flow on Doppler (Figure 2).

Clinical follow-up was indicated with periodic echocardiographic control. Symptoms responded to betablocker therapy.

\section{Discussion}

Semilunar valve alterations are among the most common cardiac malformations. In contrast to bicuspid aortic valve - present in $2 \%$ of population - the finding of a quadricuspid aortic valve is extremely rare, with an incidence between 0.008 and $0.033 \%^{1,3,4}$.

The first report of a quadricuspid aortic valve, in 1862, comes from necropsy data; and the first echocardiographic finding is from $1984^{3}$. Since then, the frequency of this diagnosis has been increasing.

Normally, it presents itself as an isolated condition but may be associated with interventricular septum defect, patent ductus arteriosus, coronary ostium alterations and other valvular defects as well ${ }^{1,4}$.

Aortic regurgitation, caused by abnormal leaflet coaptation, is common. Some authors suggest fibrous thickening ${ }^{1,4}$, while others propose unequal distribution of transvalvar stress - because of the fourth cusp ${ }^{1}-$, as the pathophysiological mechanism for valvular insufficiency. Stenosis is rare.

On echocardiography, the quadricuspid valve is identified by its characteristic " $X$ " configuration during diastole (different from the " $Y$ " of normal tricuspid aortic valve) and rectangular aspect during systole ${ }^{1,3,4}$. According to the Hurwitz and Roberts ${ }^{5}$ classification, considering the size of leaflets, only $12 \%$ of quadricuspid aortic valves have four equal-sized leaflets.

There is no agreement about which, transthoracic or transesophageal, is the best echocardiographic technique for this diagnosis. However, it is known that the use of Doppler has made the examination more sensitive in 


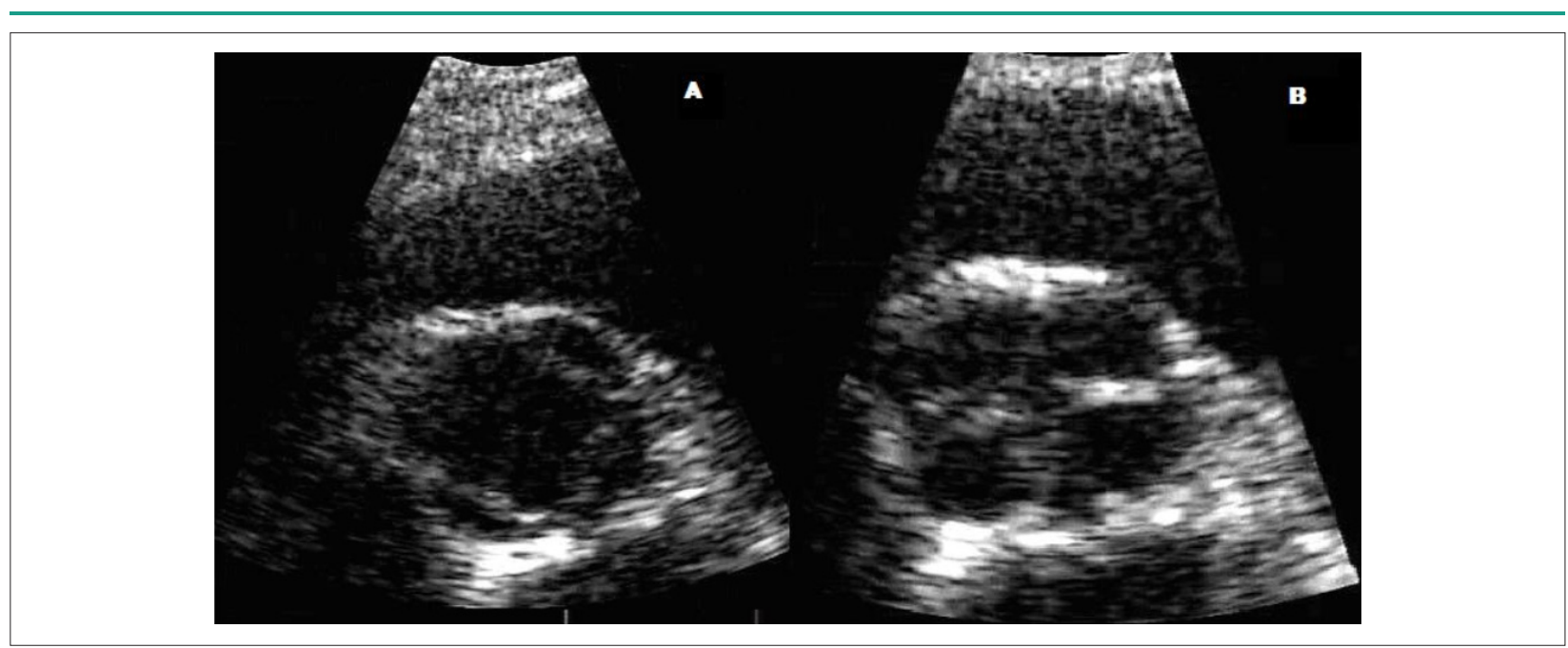

Figure. 1 - Quadricuspid aortic valve during systole, showing the typical rectangular aspect (A); and during diastole, demonstrating the "X" configuration of the four closed leaflets (B).

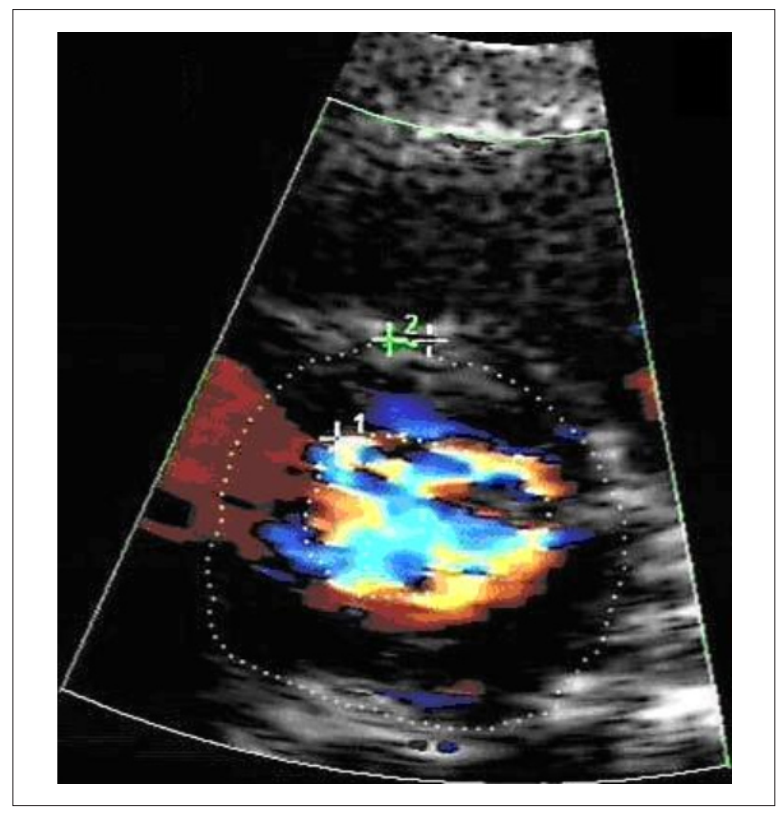

Figure 2 - Doppler image of regurgitant flow. demonstrating the retrograde flow through the valve, even when there is no clinical repercussion, facilitating early diagnosis of aortic regurgitation.

Taking into account the technological development of echocardiographic equipment, and its availability as a noninvasive diagnostic tool, it is feasible to detect, follow and diagnose possible complications of quadricuspid aortic valves even in asymptomatic individuals.

\section{Potential Conflict of Interest}

No potential conflict of interest relevant to this article was reported.

\section{Sources of Funding}

There were no external funding sources for this study.

\section{Study Association}

This study is not associated with any graduation program. 


\section{Case Report}

\section{References}

1- Feldman BJ, Khanderia BK, Warnes CA, Seward JB, Taylor CL, Tajik AJ. Incidence, description and functional assessment of isolated quadricuspid aortic valves. Am J Cardiol. 1990; 65: 937-8.

2- Robicsek F, Sanger PW, Daugherty HK, Montgomery CC. Congenital quadricuspid aortic valve with displacement of the left coronary orifice. Coll Works Cardiopulm Dis. 1968; 14: 87-90.

3- Charandrasekaran K, Tajik AJ, Edwards WD, Seward JB. Two-dimensional echocardiografic diagnosis of quadricuspid aortic valve. Am J Cardiol. 1984; 53: 1732-3.

4- Barbosa MM, Motta MS. Quadricuspid aortic valve and aortic regurgitation diagnosed by Doppler echocardiography: report of two cases and review of the literature. J Am Soc Echocardiogr. 1991; 4: 69-74.

5- Hurwitz LE, Roberts WC. Quadricuspid semilunar valve. Am J Cardiol. 1973; 31: 623-6. 